\title{
Evaluation of Quantitative and Qualitative Losses on Millet and White Rice in Storage Grains Caused by Corcyra cephalonica (Stainton) in Senegal
}

\author{
Mamadou LO ${ }^{1 *}$, Toffène Diome ${ }^{1}$, Cheikh Thiaw ${ }^{2}$, Mbacké Sembene ${ }^{1}$ \\ ${ }^{1}$ Genetics and Population Management Team, Department of Animal Biology, Faculty of Science and Technology, Cheikh Anta \\ Diop University, Dakar, Senegal \\ ${ }^{2}$ UFR Sciences and Techniques in Agronomy and Vegetable Production (STAPV), University of Sine Saloum El-Hadji Ibrahima \\ Niass (USSEIN) Sing-Sing, Kaolack, Senegal \\ Email: *laminelofa@gmail.com, toffene.diome@ucad.edu.sn, thiacheikh@hotmail.com, mbacke.sembene@ucad.edu.sn
}

How to cite this paper: LO, M., Diome, T. Thiaw, C. and Sembene, M. (2021) Evaluation of Quantitative and Qualitative Losses on Millet and White Rice in Storage Grains Caused by Corcyra cephalonica (Stainton) in Senegal. Advances in Entomology, 9, 30-43.

https://doi.org/10.4236/ae.2021.91003

Received: November 16, 2020

Accepted: January 3, 2021

Published: January 6, 2021

Copyright $\odot 2021$ by author(s) and Scientific Research Publishing Inc. This work is licensed under the Creative Commons Attribution International License (CC BY 4.0).

http://creativecommons.org/licenses/by/4.0/

\section{(c) (i) Open Access}

\begin{abstract}
In Senegal, millet (Pennisetum glaucum (L.) R. Br.) and rice (Oryza sativa (L., 1753)) are the most widely consumed foods. This study is part of improving the conservation of these two cereals in Senegal by assessing the quantitative and qualitative losses caused by a lepidopteran, Corcyra cephalonica (Stainton) subservient to millet and rice stocks. For this purpose, samples of millet and rice from an area of the center of the groundnut basin (Diourbel) were collected, sterilized in the cold and infected with C. cephalonica eggs from the same locality. These infected samples were tracked during a development period of two successive generations. The samples were scrutinized before being infected and after a larval cycle of codling moth. The results showed that rice grains are richer in water $(10.75 \% \pm 0.4249 \%$, on average) than millet $(9.40 \%$ $\pm 0.3944 \%$, on average) and the difference in rank is very significant ( $\mathrm{p}$-value $=0.0001<0.05)$. Moreover, the attack percentage on millet grains is three times higher $(36.31 \% \pm 25.18 \%)$ than rice $(12.95 \% \pm 6.69 \%)$ with a non-significant difference ( $\mathrm{p}$-value $=0.296>0.05$ ). A similar trend is observed at the loss percentage, which is four times higher with millet grains $(8.67 \% \pm 5.07 \%)$ than rice $(2.86 \% \pm 2.75 \%)$ with a non-significant difference ( $\mathrm{p}$-value $=$ $0.835>0.05)$. A multiple linear regression showed a generation effect on millet for the attack percentage and a generation and cereal effect for the percentage of weight loss on rice.
\end{abstract}




\section{Keywords}

Millet, Rice, C. cephalonica, Attack Percentage, Loss Percentage

\section{Introduction}

Losses occur at all stages, from harvesting to consumption: first at the producer, whether they are products for self-consumption, seed or waiting to be marketed; then during transport to storage locations and during storage; finally, in the reserves of traders. All these losses are all the more damaging since they affect the product once harvested; they do not only harm the peasant but also cost very much to the national economy [1]. In many developing countries, cereals and pulses are an essential part of the population's diet, especially those with lower incomes, who are generally in rural areas. In these countries, food self-sufficiency is still often a goal to be achieved, and this is not always or solely due to the inefficiency of local production systems. The magnitude of post-harvest losses sometimes severely limits the impact of efforts to increase food production; this reduces the availability of food at the local level, condemning national policies to resort to massive imports of food and thereby increasing their food dependence. Governments in developing countries, as well as many international NGOs, bilateral and multilateral cooperation organizations, and FAO in particular, have been engaged for several years in projects aimed at preventing food loss. Experiences gained through these interventions have often highlighted the need not only to improve production processes, but also to raise awareness among producers and interested institutions about the problem of post-harvest losses [2]. Thus, for farmers, it is a great pleasure to be able to admire a field of maize, sorghum or rice which is about to be harvested. But they are disappointed when sometimes they have to find out that after harvest, large part of the grain produced has been lost, or is so much damaged so that it has become unfit for consumption or sale. What happened, when did it happen? And above all, what can be done, after so much effort, so many hours devoted to the work of the fields, to avoid suffering post-harvest losses? As other crops, rice is victim of attacks from several devastating insects at different stages of its development. Among devastating insects, we find those which draw relevant attention and step in post crops stage. Their infest is at the beginning the cause of enormous qualitative losses as well as quantative noted in warehouses or storage places so reducing to almost nothing all effort devoted to the production [3]. Between the crops and consumption, more than $30 \%$ of cereal production is lost; this rate is higher in sahelian region because of the long period of storage [4]. Farmers with such problems tend to apply treatments such as insecticide spraying and fumigation [5]. [6] as well as [7] studied the biology of $C$. cephalonica on various foods such as peanuts, cocoa, maize, rice, cowpea and millet. How can we reliably assess the losses of particularly $C$. cephalonica grains due to insects on millet and rice dur- 
ing storage? Without any doubt this estimation should help us to understand clearly damages and then find solutions for participative management of devastating insects and stock food. With this in mind, this study is entitled "Assessing quantitative and qualitative losses on millet and white rice grains in storage caused by C. cephalonica (Stainton) in Senegal".

\section{Materials and Methods}

\subsection{Study Medium}

The study was done in the Laboratory of Life and Earth Sciences of the New High School of Kaolack (NLK). This environment belongs to the Sahel-Sudan area (SAS) and the experiments were made under an average temperature of $30.44 \pm 1.96$ degrees Celsius and an average relative humidity of $73.21 \% \pm 1.74 \%$. Samples of millet and rice were collected from the seed packing station in the Diourbel region.

\subsection{Material}

The biological material consisted of samples of millet and white rice, eggs of $C$. cephalonica recuperated from the clutches of females from these two cereals from the same locality. The physical material was formed by the following: plastic boxes with holed lids to facilitate the aeration of the mid $50 \mathrm{~cm}^{3}$ capacity, mating drums for egg recapture, bins to hold samples, a storage cabinet to protect samples from rodents, a refrigerator for the sterilization of the food substrate, a column of sieve to separate the moths from the cereal, mixed dishes and a clamp for sorting grains and assisted by a binocular magnifying glass, an electronic scale Jeulin: cap: $400 \mathrm{~g}$; grad: $0.1 \mathrm{~g}$ for weighing samples, $80 \mathrm{ml}$ Pyrex beakers that resist heat during heat, a test for determining the water content of samples, labels for marking samples, a GPS (Global Positioning System) for the survey of geographical coordinates.

\subsection{Methods}

\subsubsection{Sampling}

Samples of $20 \mathrm{~g}$ millet grains or white broken rice, infested with eggs from a wild strain of C. cephalonica from the seed packing station in Diourbel, located at $14^{\circ} 39^{\prime} 4.5^{\prime \prime N} ; 16^{\circ} 15^{\prime} 19.36^{\prime \prime} \mathrm{W}$ belonging to the Sahel-Sudan zone (SAS), used to study the biological parameters of dry grain moth, are collected after a first and second full cycle of larval moth development and have been used as biological material. Samples were carefully examined before contamination and after the larval moth cycle.

\subsubsection{Determining the Water Content}

A decrease in the physical substance of the product results in weight loss. However, weight loss and product loss should be distinguished. The decrease in moisture content leads to a decrease in weight, which is not a food loss. In opposition, an increase in weight by absorbing moisture, as a result of rains on an 
open-air stock, for example, can cause serious damage that will result in losses [2]. According to [8], from a biochemical point of view, organic products consist of dry matter and water. Water content refers to the amount of open water contained in a given product. The water content is expressed either by a decimal ratio or by a percentage; for example, for cereals, a 13\% moisture level is regard as a guarantee of good grain conservation. In agriculture, it is customary to indicate the water content or humidity level from the wet product, and in this case, it is defined as: the water content is the ratio between the weight of water and the total weight of dry matter and water.

Thus, to determine the water content of cereal grains, two batches of ten boxes each are recuperated. The contents of the boxes in Lot 1 are mixed to form an overall sample of $200 \mathrm{~g}$ of millet grains on the one hand, those of Lot 2 are also mixed to give an overall sample of $200 \mathrm{~g}$ of rice grains on the other.

These global samples are then sifted through a column of decreasing mesh sieve to eliminate insects in their various forms and dust. Global samples cleaned, ten Pyrex glass beakers with $80 \mathrm{ml}$ capacity are each filled with $20 \mathrm{~g}$ of millet grains and ten more of $20 \mathrm{~g}$ of rice each. These beakers are then placed in the oven at a temperature of $85^{\circ} \mathrm{C}$. After 17 hours, the samples are weighed again. The water content was assessed by the following formula:

$$
\operatorname{Te}(\%)=\frac{\mathrm{m} 1-\mathrm{m} 2}{\mathrm{ml}} * 100
$$

with: Te: water content; $\mathrm{m} 1$ : sample mass before deposition in the oven; $\mathrm{m} 2$ : sample mass at the end of the oven.

\subsubsection{Assessment of $C$. cephalonica Losses on Millet and Rice Grains}

The term "post-harvest loss" means a measurable quantitative and qualitative reduction of a given product. These losses can occur throughout the various phases of the post-harvest system. This definition must also take into account cases of product deterioration. However, it would be more accurate to speak of limitation in the use of the product than losses themselves. Grains partially damaged by insects, for example, may no longer be suitable for human consumption, or for marketing. If such were their destinations, we must admit that these are losses, even if grain can be recuperated by using them for the feeding of farm animals [2]. To measure quantitative and qualitative losses, six samples of which the first three are millet grains and the last three of rice, $10 \mathrm{~g}$ each, are taken from the initial sample (control), from the global samples used for the development of the first larval generation, and from the global development samples of two successive larval generations. The grains, after observations, are picked up, counted and weighed. The following two parameters were measured to assess losses caused by $C$. cephalonica pest of millet and rice stocks:

- The percentage of grain attacks (\% A);

- The percentage of grain weight loss (\% B).

Based on the data collected, the percentages of grain attacks were calculated after sieving using the following formula: 


$$
\% \mathrm{~A}=\frac{\mathrm{Nb} \cdot \mathrm{GA}}{\mathrm{Nb} \cdot \mathrm{GA}+\mathrm{Nb} \cdot \mathrm{GS}} * 100
$$

with: Nb.GA: the number of grains attacked; Nb.GS: the number of healthy grains.

Weight loss (expressed as \%) were calculated after each sifting from [9] counting and weighing formula follows:

$$
\% \mathrm{~B}=\frac{\mathrm{PGS} * \mathrm{Nb} \cdot \mathrm{GA}-\mathrm{PGA} * \mathrm{NGS}}{\mathrm{PGS}(\mathrm{Nb} \cdot \mathrm{GA}+\mathrm{Nb} \cdot \mathrm{GS})} * 100
$$

with: Nb.GA: the number of grains attacked; Nb.GS: the number of healthy grains; PGA: the weight of the grains attacked; PGS: the weight of healthy grains.

\subsubsection{Statistical Analysis}

The type of demonstrating used here is a multiple linear regression with $\mathrm{Y} /$ variables depending on the attack percentage $(\% \mathrm{~A})$ and the percentage of loss $(\% \mathrm{~B})$ and $\mathrm{X} /$ variables explaining the number of well grains (Nb.GS), the number of attacked grains (NB.GA), the weight of well grains (PGS), the weight of the attacked grains (PGA), the type of grain (mil and rice) and the larval generations (G0, G1, and $(\mathrm{G} 1+\mathrm{G} 2))$. Level two coactions between the factors were used in this regression with Excel and XLSTAT, which enabled the Calculations and comparison tests of the Mann Withney type as well as the ANCOVA. Square root transformation [10] was previously performed on variables to ensure compliance with the conditions of the application of the covariance analysis (normality of populations, equality of variances-populations, linearity of the relationship between the percentage of attack and the percentage of loss weight of rice and millet stocks). IBM SPSS Statistics 24 made Spearman-type correlations to verify the degree of binding between variations and to detect the significance of the test at the $5 \%$ onset.

\section{Results}

\subsection{Water Content of Millet and Rice Grains}

The water content of millet and rice grain samples was determined and the results showed that the highest water content was obtained with rice grains ranging from a minimum of $10 \%$ to a maximum of $11.50 \%$ and an average of $10.75 \%$ $\pm 0.4249 \%$, and the lowest on millet grains ranged from $8.5 \%$ to $10 \%$ with an average of $9.40 \% \pm 0.3944 \%$. Thus the grains of rice are richer in water than those of millet and the difference in rank is very significant ( $p$-value $=0.0001<$ $0.05)$.

\subsection{Losses Caused by C. cephalonica on Millet and Rice Stocks}

For all two cereals (mil and rice) and generations, the attack percentage ranges from a low of 3.83 to a high of $58.74 \%$ with an average of $24.6263 \% \pm 4.8208 \%$. The percentage of loss ranges from a minimum of 0.18 to a maximum of $13.37 \%$ with an average of $5.7275 \% \pm 4.8202 \%$. Thus the percentage of loss is less than 
the percentage of attack and its evolution follows the percentage of attack.

The number of good grains ranged from a minimum of 581 to a maximum of 1503 grains with an average of $913 \pm 375.6914$ grains; the number of grains attacked fluctuates between 24 and 1028 grains with an average of $377.375 \pm$ 409.4808 grains, this gap indicates that the data are widely dispersed around the average. This seems to be normal since cereals do not have the same nature and then grains are attacked randomly.

The weight of good grains ranges from 4.5 to $9.6 \mathrm{~g}$ with an average of $7.9 \pm$ $2.0142 \mathrm{~g}$; the attacked grain is between 0.4 and $5 \mathrm{~g}$ with an average of $2.0375 \pm$ $1.84 \mathrm{~g}$ (Table 1).

For the type of cereal, we have the same modality (50\% everywhere). However, the modality is in favour of the generations (G1 - G2) (Table 2).

\subsubsection{Comparison of Attack Percentages in Grains}

The percentage attack is three times higher on millet grains than on rice, with $36.31 \% \pm 25.18 \%$ and $12.95 \% \pm 6.69 \%$ respectively. However, the difference in degree between the percentages of attacks on millet and rice is not significant $(\mathrm{p}$-value $=0.1936>0.05)$.

\subsubsection{Relationship between Attack and Loss Percentages \\ Results for the cereal-mil group:}

The results showed that there is no relationship between the percentages of attack and loss in millet grains (Sig. $=0.2>0.05$ ).

\section{Results for the cereal-rice group:}

The results showed that there is no relationship between the percentages of attack and loss in the grains of rice (Sig. $=0.2>0.05)$.

Table 1. Statistical data of the parameters studied.

\begin{tabular}{cccccc}
\hline Variable & Observations & Minimum & Maximum & Average & Standard deviation \\
\hline$\%$ A & 8 & 3,83 & 58.4 & 24.6263 & 21.1382 \\
$\%$ B & 8 & 0,18 & 13.37 & 5.7275 & 4.8208 \\
Nb.GS & 8 & 581 & 1503 & 913 & 375.6914 \\
Nb.GA & 8 & 24 & 1028 & 377.375 & 409.4808 \\
PGS (g) & 8 & 4.5 & 9.6 & 7.9 & 2.0142 \\
PGA (g) & 8 & 0,4 & 5 & 2.0375 & 1.84 \\
\hline
\end{tabular}

Table 2. Average modalities table.

\begin{tabular}{cccc}
\hline Variable & Terms & Staff & $\%$ \\
\hline Cereal & Millet & 4 & 50 \\
& Rice & 4 & 50 \\
Generation & G0 & 2 & 25 \\
& G1 & 2 & 25 \\
& G1 + G2 & 4 & 50
\end{tabular}




\subsubsection{Decline of Variable \% A}

The best model for the chosen selection criterion is shown in bold (Table 3 ). The 2 p-values (0.0026) and (0.0046) < alpha (0.05), which implies that the influences of larval generations on the number of grains attacked on the one hand, and on the type of cereal on the other, are significantly different on the percentage attack of millet and rice grains of $C$. cephalonica (Table 4).

The effects are detailed in Table 5. In fact, the co-actions of the number of attacked grains with G0, G1 and (G1 + G2) have significantly different positive effects, while those of millet cereal with G0, G1 and (G1 + G2) have significantly different negative effects on the attack's percentage of $C$. cephalonica.

The standardized coefficient graph (Figure 1) summarizes the effect of the factors. It reveals that these effects are positive and more important with the factors Nb.GA* $(\mathrm{G} 1+\mathrm{G} 2)$, followed by those Nb.GA* G1 and lower at the level of Nb.GA ${ }^{*} \mathrm{G} 0$. However, millet cereal has a negative effect on the \%A higher at the level of cereal-mil ${ }^{\star} \mathrm{G} 1$, followed by cereal-mil ${ }^{\star} \mathrm{G} 0$ and finally lower at the level of cereal-mil * $(\mathrm{G} 1+\mathrm{G} 2)$.

Table 3. Summary of variable selection (Variable \% A).

\begin{tabular}{ccccccc}
\hline Variables & Variables & MCE & $\mathrm{R}^{2}$ & $\begin{array}{c}\text { Adjusted } \\
\mathrm{R}^{2}\end{array}$ & $\begin{array}{c}\text { AIC of } \\
\text { Akaike }\end{array}$ & $\begin{array}{c}\text { SBC of } \\
\text { Schwarz }\end{array}$ \\
\hline 2 & $\mathrm{Nb} . \mathrm{GA}^{*} \mathrm{G} /$ Cereal ${ }^{*} \mathrm{G}$ & 0.0006 & 1 & 1 & -62.6764 & -62.1203
\end{tabular}

The best model for the chosen selection criterion is shown in blue. Caption: $\mathrm{G}=$ Generation; $\mathrm{Nb} \cdot \mathrm{GA}=$ Number of Attacked Grains, Interaction.

Table 4. Analysis type III sum of squares (Variable \% A).

\begin{tabular}{|c|c|c|c|c|c|}
\hline Source & DDL & Sum of squares & Average squares & $\mathrm{F}$ & $\operatorname{Pr}>F$ \\
\hline Nb.GA ${ }^{*}$ Generation & 3 & 136.4464 & 45.4821 & 82654.7274 & 0.0026 \\
\hline Cereal ${ }^{\star}$ Generation & 3 & 41.7398 & 13.9133 & 25284.6099 & 0.0046 \\
\hline
\end{tabular}

Caption: Nb.GA $=$ Number of Grains Attacked, ${ }^{*}=$ "Co-action".

Table 5. Analysis of \% a variation parameters.

\begin{tabular}{ccccccc}
\hline & Value & $\begin{array}{c}\text { Standard } \\
\text { error }\end{array}$ & $\mathrm{t}$ & $\mathrm{Pr}>|\mathrm{t}|$ & $\begin{array}{c}\text { Lower } \\
\text { bound } \\
(95 \%)\end{array}$ & $\begin{array}{c}\text { Upper } \\
\text { terminal } \\
(95 \%)\end{array}$ \\
\hline Constant & -0.0718 & 0.0779 & -0.9225 & 0.5257 & -1.0610 & 0.9174 \\
$\mathrm{Nb} . \mathrm{GA}{ }^{*} \mathrm{G} 0$ & 0.1626 & 0.0034 & 47.9863 & $\mathbf{0 . 0 1 3 3}$ & 0.1195 & 0.2056 \\
$\mathrm{Nb} . \mathrm{GA}{ }^{*} \mathrm{G} 1$ & 0.0806 & 0.0004 & 191.2634 & $\mathbf{0 . 0 0 3 3}$ & 0.0752 & 0.0859 \\
$\mathrm{Nb} . \mathrm{GA}{ }^{*}(\mathrm{G} 1+\mathrm{G} 2)$ & 0.1388 & 0.0006 & 214.3765 & $\mathbf{0 . 0 0 3 0}$ & 0.1306 & 0.1470 \\
$\mathrm{Cereal}-\mathrm{mil}{ }^{*} \mathrm{G} 0$ & -15.3471 & 0.4382 & -35.0196 & $\mathbf{0 . 0 1 8 2}$ & -20.9155 & -9.7787 \\
$\mathrm{Cereal}-\mathrm{mil}{ }^{*} \mathrm{G} 1$ & -9.4754 & 0.0895 & -105.8220 & $\mathbf{0 . 0 0 6 0}$ & -10.6132 & -8.3377 \\
Cereal-mil ${ }^{*}(\mathrm{G} 1+\mathrm{G} 2)$ & -83.8396 & 0.5850 & -143.3039 & $\mathbf{0 . 0 0 4 4}$ & -91.2734 & -76.4059 \\
\hline
\end{tabular}

Caption: G0 = Generation 0; G1 = Generation 1; G2 = Generation 2; Nb.GA = Number of Grains Attacked, * = "interaction". 


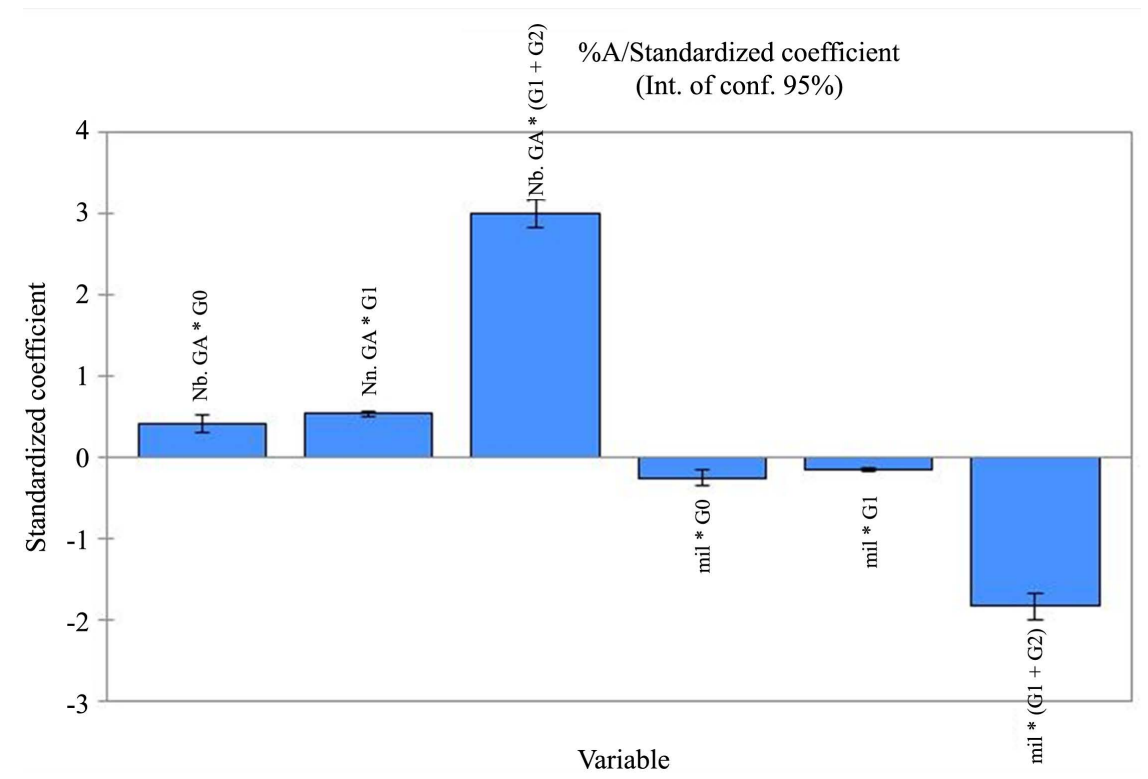

Figure 1. Chart of standardized coefficients.

In short, we can say that there is an effect of larval generations on the number of attacked grains and that is positive and significantly differ on the percentage of attack; an effect of larval generations on millet cereal that is negative and significantly different on the percentage of attack.

Analysis of Figure 2 reveals that the percentage of attack increases with the number of grains attacked. The generation $(\mathrm{G} 1+\mathrm{G} 2)$ has the highest number of attacked grains and the percentage of attack, while the G0 generation has the lowest number of attacked grains and the percentage of attack. Different generations form relatively heterogeneous groups.

\section{Graphiques des moyennes:}

Figure 3(b) confirms that the generation/cereal effect on the attack percentage is constant and zero on rice cereal. However, this effect is negative and increases from G0 to G1 and then decreases from G1 to $(G 1+\mathrm{G} 2)$ at the mil cereal level. This evolution is not linear and its decline from G1 to G1 + G2 could be explained by a mass effect. This effect on the attack percentage evolves differently in millet cereal (Figure 3(a)).

\subsubsection{Descriptive Statistics and Correlation of Loss Percentages (\% B)}

The percentage of loss is four times higher in millet grains than in rice, $8.67 \% \pm$ $5.07 \%$ and $2.86 \% \pm 2.75 \%$ respectively. They are not correlated (Sig. $=0.8>0.05$ ).

\subsubsection{Regression of Variable \% B}

The best model for the chosen selection criterion is shown in bold (Table 6). The 2 p-values (0.0007) and (0.0048) < alpha (0.05), which implies that the coactions of weight factors of good grains with the weight of the attacked grains on the one hand, generations with the type of cereal on the other, have significantly different influences on the percentage of weight loss in dry matter caused by $C$. cephalonica (Table 7). 
Regression of \% A by Nb. GA $\left(\mathrm{R}^{2}=10000\right)$

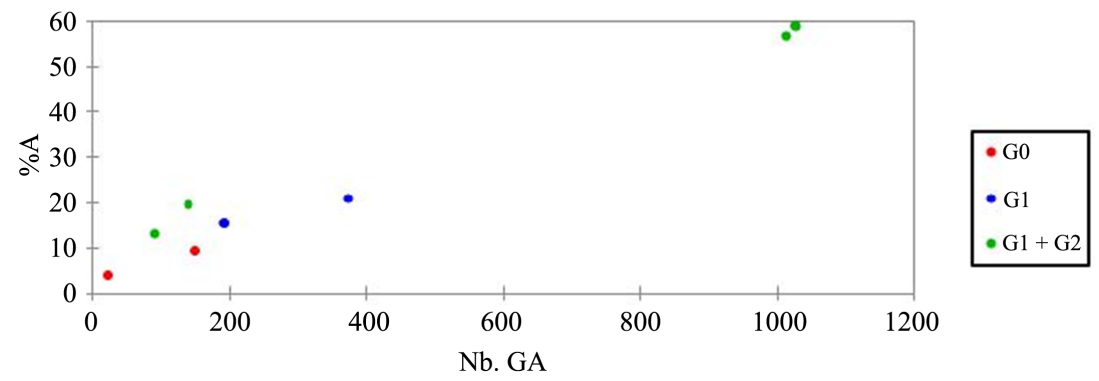

Figure 2. A cloud of points shows the change in the percentage of attack based on the number of attacked grains and generations.

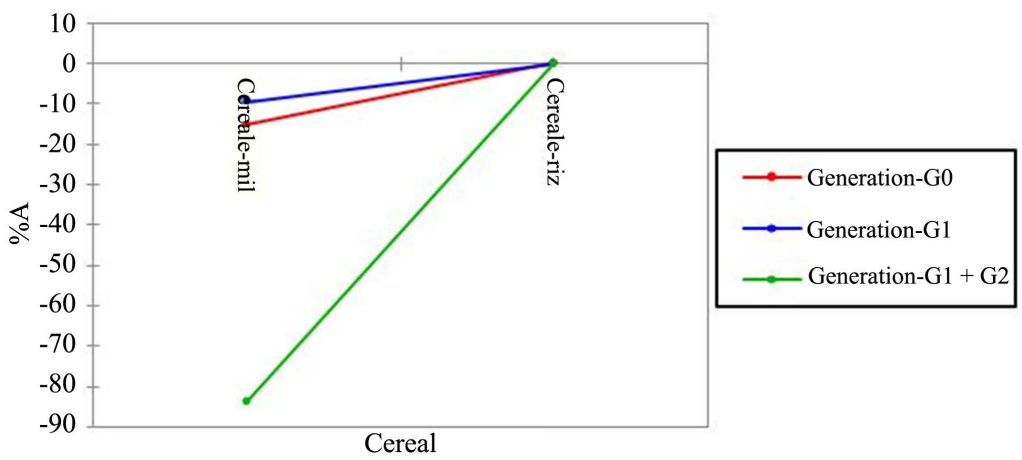

(a)

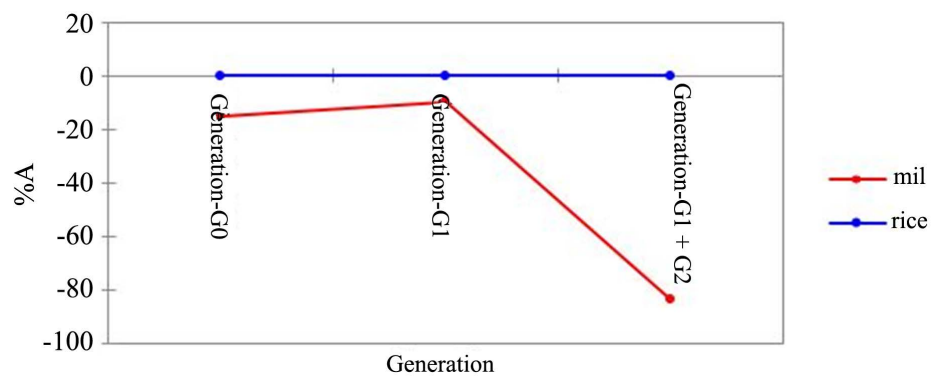

(b)

Figure 3. Graphs of the averages of variation in the effects of the grain/generation interaction on the percentage of attack. (a) and (b): Cereal * Generation.

Table 6. Summary of variable selection (Variable \% B).

\begin{tabular}{ccccccc}
\hline \multirow{2}{*}{ Variables } & Variables & MCE & $\mathrm{R}^{2}$ & $\begin{array}{c}\text { Adjusted } \\
\mathrm{R}^{2}\end{array}$ & $\begin{array}{c}\text { AIC of } \\
\text { Akaike }\end{array}$ & $\begin{array}{c}\text { SBC of } \\
\text { Schwarz }\end{array}$ \\
\hline $\mathbf{2}$ & PGS $(\mathrm{g}) *$ PGA (g)/Cereal * Gen & $\mathbf{0 . 0 0 0 2}$ & $\mathbf{1}$ & $\mathbf{1}$ & $\mathbf{- 7 1 . 1 1 6 3}$ & $\mathbf{- 7 0 . 5 6 0 2}$ \\
\hline
\end{tabular}

The best model for the chosen selection criterion is shown in bold. Caption: PGS = Healthy Grain Weight; Gen $=$ Generation; PGA $=$ Weight of Attacked Grains, ${ }^{*}=$ co-action .

Table 7. Analysis type I sum of squares (Variable \% B).

\begin{tabular}{cccccc}
\hline Source & DDL & Sum of squares & Average squares & F & Pr $>$ F \\
\hline PGS $(\mathrm{g}){ }^{*}$ PGA $(\mathrm{g})$ & 1 & 138.7215 & 138.7215 & $724,014.4724$ & $\mathbf{0 . 0 0 0 7}$ \\
Cereal $^{*}$ Generation & 5 & 23.9617 & 4.7923 & $25,012.1080$ & $\mathbf{0 . 0 0 4 8}$
\end{tabular}

Caption: PGS-Healthy Grain Weight; PGA-Weight of Attacked Grains, ${ }^{*}=$ co-action. 
The model parameter table (Table 8) shows that the sources (PGS $(\mathrm{g}) *$ PGA $(\mathrm{g})$, cereal-mil ${ }^{\star} \mathrm{G} 0$, cereal-mil ${ }^{\star} \mathrm{G} 1$, cereal-mil ${ }^{*}(\mathrm{G} 1+\mathrm{G} 2)$, cereal-rice ${ }^{\star} \mathrm{G} 0$ and cereal-rice $\left.{ }^{\star} \mathrm{G} 1\right)$ all have $\mathrm{p}$-values below the alpha meaning threshold (0.05), so they are significantly different in the percentage of weight loss in dry matter of millet and rice grains caused by $C$. cephalonica.

The standardized coefficient graph (Figure 4) showed that the sources have positive influences except for the cereal-mil ${ }^{*}(\mathrm{G} 1+\mathrm{G} 2)$ which has a negative influence. This negative aspect of this source on $\% \mathrm{~B}$ would be probably due to overcrowding in the second generation.

\section{Average charts:}

The analysis in Figure 5 shows that in millet cereal, the average influence of reciprocal grain-generation actions on the percentage of loss is higher at the generation level (G1 + G2) (12.49\%), followed by that of the G1 generation (7.15\%). and lower at the G0 generation (2.25\%).

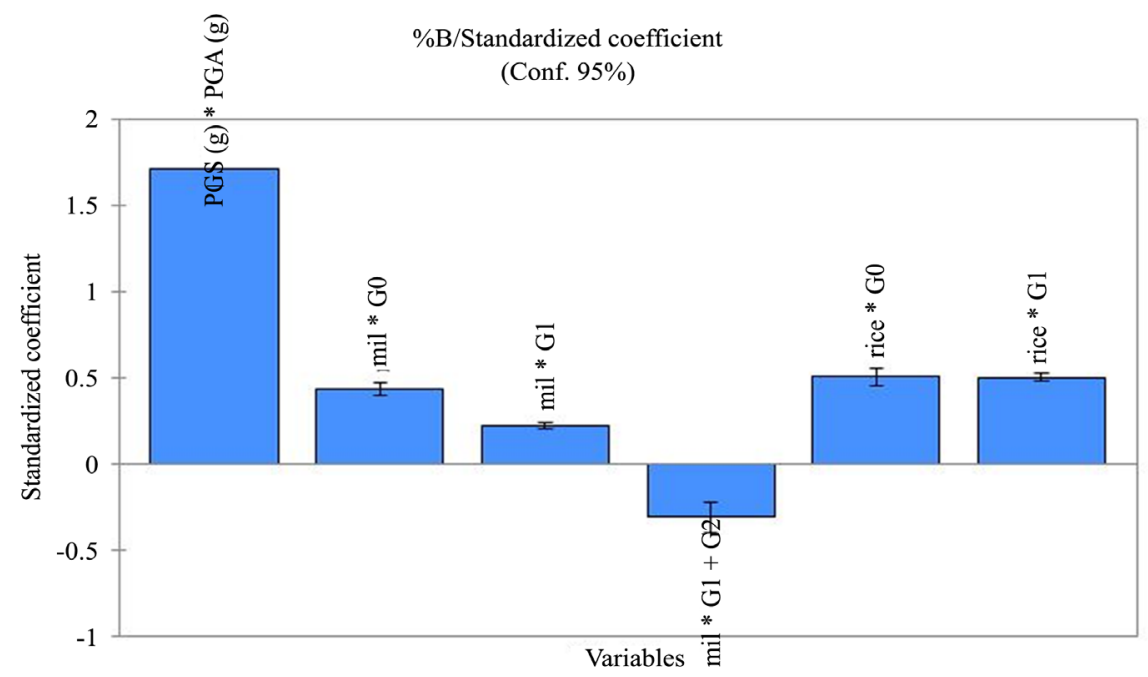

Figure 4. Chart of standardized coefficients.

Table 8. Analysis of \% B variation parameters.

\begin{tabular}{ccccccc}
\hline Source & Value & $\begin{array}{c}\text { Standard } \\
\text { error }\end{array}$ & $\mathrm{t}$ & $\mathrm{Pr}>|\mathrm{t}|$ & $\begin{array}{c}\text { Lower } \\
\text { bound } \\
(95 \%)\end{array}$ & $\begin{array}{c}\text { Upper } \\
\text { terminal } \\
(95 \%)\end{array}$ \\
\hline $\begin{array}{c}\text { Constant } \\
\text { PGS }(\mathrm{g}){ }^{*} \mathrm{PGA}(\mathrm{g})\end{array}$ & -11.1734 & 0.0756 & -147.7179 & $\mathbf{0 . 0 0 4 3}$ & -12.1345 & -10.2123 \\
cereal-mil ${ }^{*} \mathrm{G} 0$ & 5.9094 & 0.0380 & 155.3909 & $\mathbf{0 . 0 0 4 1}$ & 5.4262 & 6.3926 \\
cereal-mil ${ }^{*} \mathrm{G} 1$ & 3.0876 & 0.0188 & 164.5059 & $\mathbf{0 . 0 0 3 9}$ & 2.8491 & 3.3261 \\
cereal-mil ${ }^{*}(\mathrm{G} 1+\mathrm{G} 2)$ & -3.1782 & 0.0727 & -43.7441 & $\mathbf{0 . 0 1 4 6}$ & -4.1013 & -2.2550 \\
cereal-rice ${ }^{*} \mathrm{G} 0$ & 6.9212 & 0.0536 & 129.1414 & $\mathbf{0 . 0 0 4 9}$ & 6.2402 & 7.6021 \\
cereal-rice ${ }^{*} \mathrm{G} 1$ & 6.8753 & 0.0250 & 275.0169 & $\mathbf{0 . 0 0 2 3}$ & 6.5577 & 7.1930 \\
\hline
\end{tabular}

Legend: PSG = Weight of Healthy Grains; G0 = Generation 0; G1 = Generation 1; G2 = Generation 2; PGA

$=$ Weight of Attacked Grains, ${ }^{*}=$ co-action. 
On rice cereals, on the other hand, this average is higher in the G1 generation (6.09\%), followed by that of the generation (G1 + G2) (2.59\%). and lower with generation G0 $(0.18 \%)$ (see Figure $5(\mathrm{a})$ ). Note that all averages are higher with millet cereal than rice cereal. The intersection between the G1 and (G1 + G2) generations reflects a state of conflict of these generations with rice cereal. This would be probably due to a mass effect that occurred during the second generation with rice cereal and is the opposite of what we observed on the percentage of attack on millet cereal. Figure 5(b) revealed a growing and linear evolution of the effects of cereal-generation co-actions on the percentage of loss (ranging from G0, G1 to $(\mathrm{G} 1+\mathrm{G} 2)$ ) with millet cereal. However, this development is not linear with rice cereal; it increases from G0 to G1, then decreases from G1 to (G1 $+\mathrm{G} 2)$.

Thus, we can talk about a single generation effect on millet cereal and a cereal and generation effect on rice cereal.

Figure 6 associated with the synthesis of the effect of cereal-generation interdependence shows that factors evolve in the same way on average at the attack percentage, but evolve differently in terms of the percentage of loss.

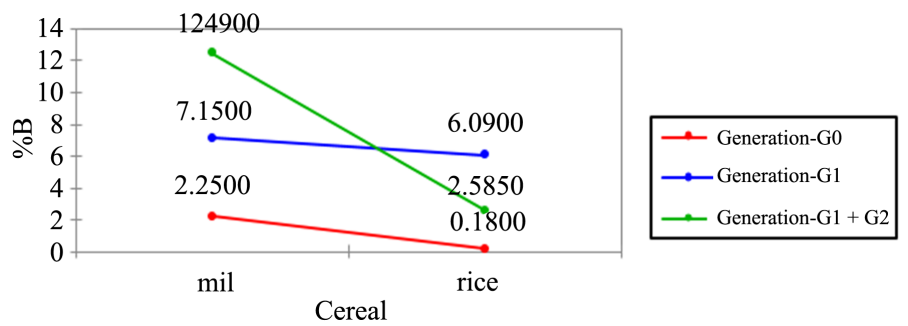

(a)

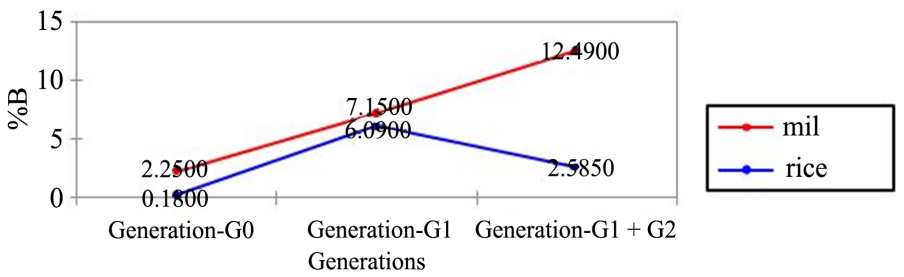

(b)

Figure 5. Graphs of averages illustrating the effects of cereal-generation interactions on the percentage of dry matter losses. (a) and (b): Cereal ${ }^{\star}$ Generation.

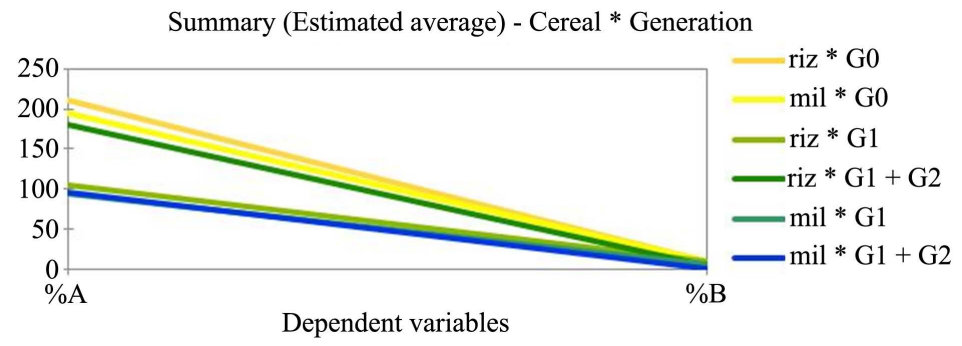

Figure 6. Changes in attack and loss percentages based on the interdependence of grain type with generations. 


\section{Discussion}

Rice (Oryza sativa L.) and millet (Pennisetum typhoid Stapf. and Hubb.), stored are attacked by a wide range of insects whose identities and modes of attack differ from those encountered in the field. These are mostly polyphage insects attacking not only these two grains in stock, but also other stored grains. Among these insect pests, Corcyra cephalonica is arguably one of the most formidable that can result in both significant quantitative and qualitative losses during storage. [11] reports that $C$. cephalonica larvae are capable of damaging intact grains and feed on the surface and inside the seeds. They spin a silky, resistant fiber, bloody together the grains, feces and skins of molded larvae.

Of our results, the water content $(T e)$ is higher on rice grains $(10.75 \% \pm$ $0.4249 \%)$ millet $(9.40 \% \pm 0.3944 \%)$ with a very significant difference ( $\mathrm{p}$-value $=$ $0.0001<0.05)$. These values are high and can result in considerable losses during storage.

According to [12], a study conducted at the Agrhymet Meteorological Centre in Niamey, Kotomgonde in 1978 showed that for cereals the water content varies from $3 \%$ to $5 \%$ in banco attics, $3 \%$ to $6.1 \%$ in straw attics during the dry season. It is during the rainy season that insects damage grains in attics because of the increasing humidity of the air and making the grains less hard.

Our results showed that the attack percentage can vary from $3.83 \%$ to $58.74 \%$ and the percentage of loss from $0.18 \%$ to $13.37 \%$ for both cereals.

The percentage of attack is three times higher on millet grains $(36.31 \% \pm$ $25.18 \%)$ than in rice $(12.95 \% \pm 6.69 \%)$ with a non-significant difference ( $\mathrm{p}$-value $=0.296>0.05)$. A similar trend is observed in the percentage of loss, which is four times higher in millet grains $(8.67 \% \pm 5.07 \%)$ than rice $(2.86 \% \pm 2.75 \%)$ with a non-significant difference ( $\mathrm{p}$-value $=0.835>0.05$ ). This would be due to the pounding operations carried out on millet grain and which would weaken this cereal so that its grain still retains its envelopes. As the white rice grain is polished and smooth, this texture would probably cause the lower percentages of attack and loss for this cereal. The results of [3] corroborate our results by showing that paddy rice had the highest values at $8.25 \%$ and $6.89 \%$ respectively for attack rates and weight loss of stocks. In contrast to shelled rice, which had the lowest values of $1.3 \%$ and $0.69 \%$, respectively for attack rates and weight loss. According to [13], adult survivors of insect pests often hide in envelopes. Which supports our result. [8] and [14] mention that for all cereals, rice in particular, studies agree that overall loss rates are about $15 \%$, with significant variability between countries, climatic zones and processes. This would mean that the rice borer would have a significant share of the $15 \%$ loss on rice grains.

In additional, the percentages of attack and loss in the grains are not correlated.

The results of the ANCOVA show that the coactions of the factors number of grains attacked and the larval generations on the one hand, the type of cereal and the larval generations on the other, have significantly different influences on 
the percentage of attack of $C$. cephalonica on millet and rice grains.

Indeed, interactions of the number of grains attacked with larval generations have positive effects, while those of millet cereal with these same generations have negative effects on the percentage of attack of $C$. cephalonica.

The effect of cereal-generation interdependence on the attack percentage is constant and zero on rice cereal. However, its evolution is not linear and shows a mass effect that occurred during the second generation in millet grains. This allows us to say that the effect of cereal-generation interdependence on the attack percentage evolves differently in millet cereal. We can talk about a generation effect on millet for the attack percentage.

From our results, the coactions of factors: the weight of healthy grains with the weight of the attacked grains on the one hand, the generations with the type of cereal on the other hand, have significantly different influences on the percentage of weight loss in dry matter caused by $C$. cephalonica. These influences are positive with the exception of the factor cereal-mil * $(G 1+G 2)$ which has a negative influence.

This negative aspect of this source on $\% \mathrm{~B}$ would likely be due to overcrowding in the second generation, as we have observed for the attack percentage. This same effect is recorded during the passage between the G1 and (G1 + G2) generations in the rice grains.

The effects of cereal ${ }^{*}$ Generation interdependence on the percentage of loss in millet cereals are increasingly and linearly changing, and differently in rice grains. These observations allow us to talk, in terms of the percentage of loss, of a single generation effect on millet cereal and a grain and generation effect in rice cereal.

\section{Conclusion}

Two types of effects were noted in this study: a generation effect on millet for the attack percentage and a generation and cereal effect for the percentage of weight loss on rice. Particular attention should be paid to the affinity of the moth of the grains with millet grains, where the attack percentage and weight loss are higher. The study also showed that long-term conservations increase the generations of the pest as well as the effect of generational and cereal interaction on the quantitative and qualitative losses of stored foodstuffs, as well as the occurrence of a mass effect on insect populations. A focus on the molecular biology of C. cephalonica would provide a better understanding of the ecology of C. cephalonica with respect to millet and rice food substrates.

\section{Conflicts of Interest}

The authors declare no conflicts of interest regarding the publication of this paper.

\section{References}

[1] Sembéne, M. (1996). Post-Harvest Losses: The Example of the Peanut Sparrow 
(Caryedon serratus OL.) in Senegal. ORSTOM, Dakar, 11 p.

[2] FAO (1992) Post-Harvest Grains-Organization and Techniques. In: FAO Agricultural Services Bulletin 93. Rome, 1-10. http://www.fao.org/3/t0522f/T0522F01.htm

[3] Chougourou, D.C., Ahoton, L.E., Adjou, E.S., Zoclanclounon, A.B. and Kpoviessi, D.A. (2017) Entomofauna and Damage Assessment of Insect Pests of Different Forms of Rice Conservation (Oryza sativa Linné) in South Benin. Benin Agricultural Research Bulletin (BRAB), 82, 49-58.

[4] Akintayo, I., Cisse, B. and Zadji, L.D. (2008) Guide pratique de culture des NERICAs de plateau. Manuel du centre de riz pour l'Afrique ADRAO, Cotonou (Bénin), $28 \mathrm{p}$.

[5] Zoclanclounon, A. (2012) Test d'efficacité de quatre extraits végétaux dans le contrôle de Callosobruchus maculatus Fabricius (Coleoptera: Bruchidae). Mémoire de fin de formation pour l'obtention du Diplôme d'Ingénieur de Conception à l'Ecole Polytechnique d'Abomey-Calavi. UAC, Bénin. 54 p.

[6] Mbata, G.N. (1989) Studies on Some Aspects of the Biology of Corcyra cephalonica (Stain.). Review of Applied Entomology, 78, 793.

[7] LO, M., Diome, T., Thiaw, C. and Sembéne, M. (2020) Study of the Development Parameters of Corcyra cephalonica (Stainton) According to the Type of Food Substrate. International Journal of Zoology Studies, 5, 35-41.

[8] Grolleaud, M. (2002) Post-Harvest Losses: Discovering the Full Story. Overview of the Phenomenon of Losses during the Post-Harvest System. FAO, Agro Industries and Post-Harvest Management Service, Rome.

[9] Adams, J.M. and Schulten, G.G.M. (1978) Pertes causées par les insectes, les acariens et les micro-organismes. In: Harris, K.L. and Lindblid, C.J., Eds., Post Harvest grain Loss Assessment Methods, St. Paul, 83-89.

[10] Crawley, M.J. (2007) The R Book. John Wiley and Sons, Ltd., Chichester.

[11] Dick, K.M. (1987) Losses Caused by Insects to Groundnut Stored in a Ware House of India. Tropical Science, 27, 65-75.

[12] Alzouma, I. (1990) Post-Harvest Situation in Sahelian Africa. In: Post-Harvest in Africa. Acts of the International Seminar, Abidjan, 22-28.

[13] Camara, A. (2009) Fight against Sitophilus oryzae L. (Coleoptera: Curculionidae) and Tribolium castaneum Herbst (Coleoptera: Tenebrionidae) in Rice Stocks by the Traditional Low Guinea Boiling Technique and the Use of Vegetable Essential Oils. Ph.D. Thesis, University of Quebec, Montreal.

[14] Liang, L., et al. (1993) China's Post-Harvest Grain Losses and the Means of Their Reduction and Elimination. Jingii Dili (Econ. Geogr.), No. 1, 92-96. 